\title{
MODERN METHODS APPLIED IN TEACHING PHYSICS
}

This paper deals with modernization of teaching acoustics. We prepared the study material with qualitative exercises. In the text we pay attention to physical and ecological aspects of sound and noise. Further we analyze sound as an example of mechanical waves. The main part of the work is creation of video experiments in the field of acoustics as well as experiments supported by the computer software that would enable analysis of sounds and sound filters. We created ten experiments and further developed them into methodological and study material.

Keywords: physical experiments, video experiments with sound.

\section{Introduction}

Physics and mathematics provide the foundation for further technical and technological subjects. That is why sufficient time should be invested in order to make students understand the rules and relations in physics. However, many experts disagree with the above and little time is provided for physics. Reduction of time assigned for physics education has been ongoing. Another problem is a broad variation in subject knowledge of students coming from different types of secondary schools. At some of them the level of the knowledge is still very low and has been decreasing. Most students come from secondary schools where physics is considered an optional subject. In a better case physics is taught at schools for a period of two years. Therefore, there is no real foundation to be built on. Only a small number of students come from secondary grammar schools where a sufficient base is provided with respect to physics [3].

Unfortunately, universities these days increasingly accept students for studying at their institutions in accordance with requests of society and not students' knowledge level. As a result the level of university education has been increasing. It is in particular visible at the technical universities as this type of education is neither very popular nor lucrative for contemporary students. [7].

\section{Acoustics}

At our university acoustic is studied as a part of physics where the latter is a core subject of every field of studies. Preceded by the topics on "oscillation and waves", this part of physics confronts students with the most difficult math functions. Therefore, it is very important to familiarize them with the topic in question in a more approachable manner.
Within their further professional specialization, students in secondary education can opt for subjects based on acoustics, such as physics of musical instruments, experimental non-destructive methods, acoustics, selected chapters on building and architectural acoustics.

Despite the limited time provided for teaching, it is our attempt to explain the students in the most approachable manner the basics of physical and acoustic knowledge and its practical application. Therefore, our aim is to create a complex study material related to this part of physics which could be used in higher levels of secondary grammar schools. It consists of learning material, problem solving assignments and physical experiments.

\section{Qualitative assignments}

Qualitative assignments in physics support both the deepening as well as strengthening of students' understanding of new knowledge. It allows to verify students' knowledge and their ability to apply it. Further, the assignments increase students' interest in subject and support an active understanding and application of learnt material during the teaching process. Qualitative assignments have a significant impact on the development of physical thinking. The assignments solved by the simple physical reflection are the ones most commonly used at schools. These assignments begin with the question "Why?" Questions of this type lead to looking for consequential connections and mutual relations between individual physical actions.

While solving qualitative assignments students are forced to get a deeper insight into the problematic situation. In many cases they realize that they do not understand it as well as they initially thought. A great advantage of qualitative assignments is a practical

\footnotetext{
* Miroslav Nemec

Department of Physics, Electrical Engineering and Applied Mechanics, Faculty of Wood Science and Technology, Technical University in Zvolen,

Slovakia, E-mail: mnemec@acoustics.sk
} 
application of theoretical knowledge. At the same time the accuracy of learnt theories is verified. Solving qualitative assignments allows students to analyze situations; it helps to develop their logical thinking, contrivance and creativity. By applying physics they learn to explain everyday natural occurrences as well as those from technical environment. This also prepares them for a practical life. In order to preserve a learning function of the qualitative assignment, teacher is responsible for specifying its aims. In this case the assignment carries out a didactical function and follows didactical aims of the class. Again, when working on the assignments it is important to follow a certain algorithm of individual tasks.

\section{Experiments}

One of the most important parts of physics education is its experimental element. Experiments visually demonstrate events and occurrences described by physical laws, principles as well as mathematical relations. Their importance has been gradually increasing. At the present we deal with experiments from the field of acoustics. This is in form of sound recordings followed by the analysis which is used to explain basic expressions from acoustics as well as by video experiments. Application of these experiments can prepare students for possible problems, they may experience in life [5]

It is possible to use such experiment in various stages of a lesson - presentation of a new topic, repetition, etc. It is only up to the teacher when he/she will use it. Before the integration of video experiments into physics teaching students must have made experience with conducting of classical experiments. If not computer might have become dominant focus of student's experimental activity and physics substance of the experiment would not be so important for him [6].

Multimedia technologies have shown their potential in the teaching of scientific subjects. New techniques attract students' attention, enabling an easier and rapid process of learning. Physics and technology are often considered to be difficult subjects. Interactive multimedia tools with computer presentations, simulations, animations and movies are particularly effective in physics teaching. It is very important to use these tools in other subjects, including basic education, to make science and technology more appealing and to address the scientific apathy crisis of young people [4].

\section{Experiments Requiring Frequential Analysis}

The frequential analysis of sounds is a suitable method for motivation and development of manual skills and intellectual capabilities of students from a very young schooling age. By gradual acquisition of knowledge from physics (or acoustics) and development of mathematical functions this method can be used in higher education courses.

\section{Videoexperiments}

Some experiments are carried out as video experiments. It is possible to project these experiments at schools where it would not be possible to perform them practically. By means of video experiments students obtain better comprehension as well as get an idea of application of physical principles and laws.

The experiments deal with the measurement of sound velocity in a metal rod using Kund's tube, measurement of sound velocity in the air using an open resonator - $\mathrm{U}$ tube, examination of sound pressure level in relation to distance by a sound level meter, Doppler effect, examination of the tone frequency in relation to string tension, creation of beats, creation of Chladni patterns which can be used as a nondestructive method of material properties measurement.

For each experiment students' and teacher's guide are prepared and their structure is designed so that it follows mentioned stages of conducting the experiment. A problem solving task for students is given at the beginning of each guide. Students have to find the solution by conducting the experiments [6].

Experiment is presented here by a short version of student's guide.

\section{Chladni patterns}

Chladni patterns are named after Ernest Chladni, who published these patterns in 1787 in writing "Discoveries in Sound Theory", in which the patterns were described as well as the way how they can be made. People were with Chladni patterns so fascinated, that for Chladni it was possible to earn enough money through his performances as a teacher and demonstrator. Even Napoleon said: "This man has propagated tones."

What practical significance do Chladni patterns have?

How will the grains behave in antinodes and nodes?

\section{A little bit of theory at the beginning}

Chladni patterns are a classic undergraduate demonstration. You can visualize the nodal lines of a vibrating elastic plate by sprinkling sand on it: the sand is thrown off the moving regions and piles up at the nodes. Normally, the plate is set to vibrate by bowing it like a violin. It helps to put your fingers on the edge to select the mode you want, much like fingering the strings of a violin. This takes some practice.

Indication of modes (ways of vibration) on plates with too small thickness related to total proportions. Measurement equipment contains tone generator as a source of harmonic signal and amplifier which amplifies signal coming to loudspeaker. Frequency in generator is changed continuously till the point when on the plate powdered by e.g. tea doesn't occur demanded shape of mode. Čulík and Danihelová describes Chladni patterns in more detail $[1,2]$.

You can make a nice modernized version of this demonstration using an electromagnetic shaker (essentially a powerful speaker).

What do you need?

tone generator, loudspeaker, resonance plates, sawdust particle 
The schema of the experiment

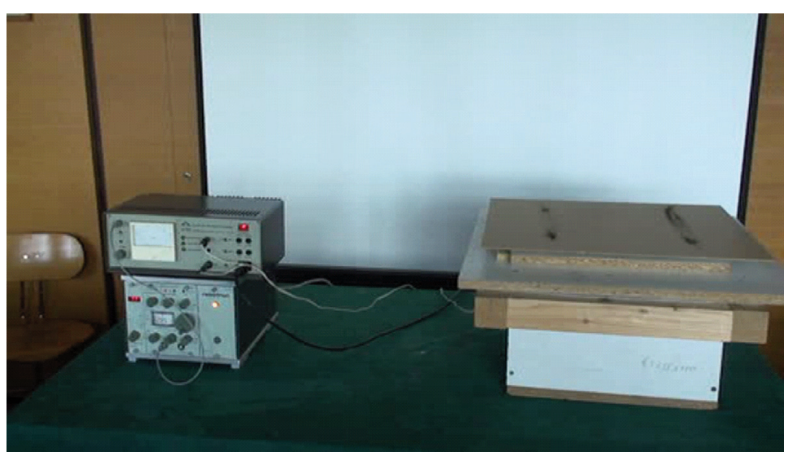

Fig. 1 Chladni's patterns

\section{How to proceed}

1. Prepare the equipment according the schema. You can use different thin metal, wooden or plastic plates.

2. Tune the tone generator on a low frequency; increase it gradually and observe the behaviour of the plate and grains.

3. If the grains start to make a characteristic pattern, fine tune the frequency and make a characteristic Chladni pattern with grains centred in the node lines.

4. Increase the frequency and make further characteristic patterns with a different number of node lines (different characteristic modes).

\section{Conclusion}

The use of created experiments was verified in the practice. It was discovered that acoustic experiments in the teaching process increase the level of clearness of the dealt topic and also the students' attention. The experiments force the students to work and think independently and help to show the connection between physical theory and everyday life in nature, mechanics and society. Some lesson experiments were carried out practically, some as video experiments. In carrying out of experiments the students' worksheets and guidelines for teachers were available. Students were actively involved in every stage of experiments and in using video experiments the projection was sporadically sopped and properly supplemented with teacher's comments, in some cases with discussion.

The results of observations showed, that students are more attentive and active when experiments, especially the ones connected with practice and everyday life, are used. Furthermore, also such students, who are not very much interested in physics and have worse notes, are involved in experiments solving.

To conclude, our aim is to create a complex study material from the field of acoustics. This would contain teaching material, qualitative assignments and experiments. The main importance is put on the experimental element in particular. Gradually, we shall create a similar material from other fields of physics with a focus on qualitative assignments, video experiments, simulations and experiments supported by computers.

\section{References}

[1] CULIK, M.: Influence of Spruce Wood and Bracing Construction on the Tone Quality of Acoustical Guitars Top Plates. In: Proceedings of the ACOUSTICS High Tatras 2009, $34^{\text {th }}$ International Acoustical Conference - EAA Symposium" [CD Rom]. Novy Smokovec: Technická Univerzita, 2009. ISBN 978-80-228-2031-8

[2] DANIHELOVA, A: Relevant Physical Acoustics Characteristics of Spruce Wood as a Material for Musical Instruments. In: Proc. of the $8^{\text {th }}$ World Conference on Timber Engineering wcte 2004, Lahti, Finland, 2004, p. 491-494, ISSN 0356-9403, ISBN 951-758-444-X

[3] HOCKICKO, P.: Frequency Analysis of Sounds (in Slovak). Proc. of the 4th International Symposium MAP 2008, Zvolen, ISBN 978-80-228-1911-4.

[4] HOCKICKO, P.: Useful Computer Software for Physical Analysis of Processes. In: Proc. of the 2009 Information and Communication Technology in Education (ICTE) Annual Conference, 15th-17th September 2009, Roznov pod Radhostem, 103-107, ISBN 978-80-7368-459-4

[5] KRISTAK, L.: Teaching Supported by Tasks and Experiments in Physics. In: Proc. of $16^{\text {th }}$ Conference of Czech and Slovak Physicists, Hradec Kralove, 2008, ISBN 80-86148-93-9.

[6] KRISTAK, L., PFEFFEROVA, M.: Computer Based Experiments in Oscillation and in Nuclear Physics at Secondary School. In: Proc. of ICTE, 2006, Roznov pod Radhostem, ISBN 80-7368-199-4

[7] NEMEC, M.: Physics at Technical University in Zvolen, Proc. of $16^{\text {th }}$ Conference of Czech and Slovak Physicists 2009, Hradec Kralove, ISBN 80-86148-93-9. 